\title{
Estudio arqueohistórico y analítico de un conjunto de vidrios de la villa romana de El Saucedo (Talavera La Nueva, Toledo).
}

\author{
R. CASTELO RUANO', C. GUTIÉRREZ NEIRA' ${ }^{2}$ J. BARRIO MARTÍN ${ }^{1}$, J. HURTADO AGUÑ $A^{3}$, \\ A. I. PARDO NARANJO', A. LÓPEZ PÉREZ ${ }^{3}$ Y R. GARCÍA GIMÉNEZ ${ }^{4}$
}

Los mejores profesores son aquellos que saben transformarse en puentes, y que invitan a sus discípulos a franquearlos. (Nikos Kazantzakis)

\begin{abstract}
Resumen
En este artículo presentamos un estudio arqueológico y analítico sobre los vidrios documentados en la villa de El Saucedo (Talavera la Nueva, Toledo) en las campañas arqueológicas realizadas entre 2003-2006. Hemos seleccionado vidrios de época altoimperial, bajoimperial y visigoda. Las producciones corresponden a vajilla de mesa, adorno personal y material constructivo. El estudio tipológico y funcional se acompaña de un estudio arqueométrico donde se han utilizado la técnica MEB-EDX para conocer su composición elemental, así como de la cromatografía de gases para determinar el contenido del ungüentario de época altoimperial.
\end{abstract}

Palabras clave: vidrios romanos, El Saucedo, arqueometría, MEB-EDX, cromatografía de gases.

\section{Summary}

This article presents an archaeological and analytical study of glass fragments recovered in the archaeological excavations from 2003 until 2006 in the site of El Saucedo (Talavera la Nueva Toledo). A group of selected glasses from the early imperial, late imperial and Visigoth epochs, including tableware, personal adornments and building material, has been analyzed using MEB-EDX and gas chromatography in order to complete the typological and functional studies. The former technique has been used for the determination of the elemental composition and the second one for the identification of the contents into an ointment from the early imperial epoch.

Keywords: Roman Glasses, El Saucedo, archaeometry, MEB-EDX, gas chromatography

\section{EL CONTEXTO ARQUEOLÓGICO.}

El enclave arqueológico de El Saucedo está situado en el conventus Emeritensis, en plena llanura aluvial de la margen derecha del Tajo a unos tres kilómetros escasos de su curso actual y a unos $5 \mathrm{~km}$. de Talavera de la Reina, la antigua Caesarobriga y junto al arroyo Baladíes o Albaladiel. En el yacimiento de El Saucedo se han podido detectar tres fases de ocupación que resumimos en el siguiente cuadro:

\section{FASE I}

No hay constancia alguna de estructuras arquitectónicas perteneciente a este periodo. Tan solo se han podido documentar algunas monedas y diversas piezas cerámicas y de vidrio procedentes de basureros distribuidos por diferentes zonas del yacimiento y fechadas entre la segunda mitad del siglo I y último cuarto del siglo II d.C.
1 Dpto. Prehistoria y Arqueología. UAM.

2 SECYR. UAM.
3 Proyecto" Saucedo".

4 Dpto. Geología y Geoquímica. UAM. 


\section{FASE II}

A finales del s.III principios del siglo IV d.C. se edificó una villa palaciega, un centro aristocrático sobre un establecimiento más antiguo que no tiene porqué implicar continuidad respecto al anterior en términos de propietarios. Esta monumentalización es contemporánea a la vitalidad que experimentó Caesarobriga a partir del siglo IV d.C. Se trata de una villa aúlica de gran riqueza monumental. Se puso especial atención en la construcción de la pars urbana, conforme a criterios arquitectónicos y decorativos largamente meditado de la privata luxuria, al servicio de su propia ideología de clase, y en consecuencia, con un alto componente de autorrepresentación y prestigio, con una escenografía creada exprofeso. Su programa ornamental responde a un proyecto amplio y ambicioso que demuestra que el dominus conocía los opera nobilia y que se envolvió en un halo de prestigio en el que exalta su humanitas.

\section{FASE III}

A finales del siglo V, comienzos del VI d.C., el apodyterium/frigidarium del conjunto termal fue remodelado para convertirlo en una basílica de culto cristiano con una piscina bautismal de inmersión, mientras que algunas salas de recepción y aparato. Como el oecus, serán utilizadas como zona de horreum, creándose un aprisco en el que se documentaron los restos óseos de un individuo infantil, muerto por decapitación y un rebaño formado por ovejas y cabras.

Esta transformación de El Saucedo está en consonancia con la iniciativa de las autoridades eclesiásticas, que a partir del siglo $\mathrm{V}$, empiezan a tejer en el territorio una red eclesiástica de iglesias rurales con función de curia pastoral. Será en torno al siglo $\mathrm{V}$ cuando se constate, también, en Talavera un cambio en la topografía urbana ya que espacios privados son convertidos en iglesias visigodas.

A principios del s. VIII el edificio de Saucedo sufre un importante incendio que destruye toda la zona de almacenes. El incendio es la manifestación principal de la destrucción al final de los tiempos visigodos y la transición a la Edad Media. Presidida por el dominio musulmán de la península, dominio que en Talavera está fechado en torno al 713 d.C.

\section{EL VIDRIO ALTOIMPERIAL.}

Entre los vidrios documentados en las campañas de 2003 a 2006 tan solo podemos mencionar la identificación de una pieza (2004.93 / SECYR340), se trata de un ungüentario, forma Hayes 624 y 8/27 Isings (vid. Fig.9). Su cronología abarca los siglos I al III d.C., con alguna perduración posterior. Alcanzan su máxima difusión en época flavia, en la segunda mitad del siglo I d. C. En cuanto a su filiación derivan de los alabastrones egipcios (Caldera de Castro, 1988, 174-174). En un principio fueron fabricados a molde, utilizándose en menor número, al requerir un mayor tiempo de fabricación y, por tanto, iban destinados a una minoría. Con la difusión del vidrio soplado, los ungüentarios serán de peor calidad y en consecuencia más baratos y más asequibles a un mayor número de personas (Alonso Cereza, 2010). Fueron utilizados en la barbería, el gimnasio, los baños y en el ámbito funerario, en éste último caso para perfumar al difunto durante las ceremonias previas a la inhumación o cremación, e introducidos, posteriormente, en el interior de la tumba (Palop Fernández, 2007).

$\mathrm{Su}$ contexto habitual de aparición es el mundo funerario. Se trata de piezas que antiguamente se las denominaba como lacrimatorios. Se caracterizan por presentar la base ligeramente aplastada, generalmente redondeada, tal y como ocurre en nuestro caso, el cuerpo tubular con un estrangulamiento en el tercio superior y borde con ligero vuelo. Fue la forma más difundida tanto en el este como en el oeste del imperio. Sería interminable hacer una relación exhaustiva de todos los lugares donde han sido hallados. En Hispania, se dan abundantemente en Ampurias, Lucentum, Alcoy, Tossal y Elche. Corresponde a la forma Hayes 624 y 8/27 Isings. Los ungüentarios con esta tipología tienen su máxima difusión en época flavia, en la segunda mitad del siglo I d.C.

Se trata de piezas de pequeño tamaño, con poca capacidad y normalmente provistas de boca y cuello estrechos, características ideales para su uso en cosmética.

Con el fin de comprobar si nuestro ejemplar conservaba restos del contenido que podría haber almacenado, realizamos un análisis cromatográfico para diferenciar componentes orgánicos. Los compuestos identificados fueron los siguientes: ester metílico del ácido pelargónico; ester metílico de ácido laúrico; ester metílico del ácido cáprico; ester metílico del ácido esterático. 
De los análisis e interpretación de la figura 1 adjunta se puede decir que se trata de una muestra muy homogénea donde los ácidos grasos identificados se presentan en el ámbito vegetal comúnmente, sobre todo en relación con aceites vegetales. El ácido pelargónico tiene carácter aromatizante, el ácido laúrico se emplea en cosmética y se extrae del aceite de nuez de coco o laurel; el ácido cáprico se utiliza en cosmética y perfumería. Los compuestos de $\mathrm{C} 17$ heptadecanoico o ácido margárico se usan en los ungüentos. El ácido esteárico es el más común que se encuentra en grasas vegetales, su uso es muy frecuente en cosmética. Por todo ello, se puede pensar que se trata de un resto de cosmético de origen vegetal con olor a fruta. El aceite esencial del laurel, por su riqueza de aromas está presente en muchos productos de perfumería para elaborar cremas y lociones, no solo por tener un olor característico sino porque resulta adecuado en el tratamiento externo de las afecciones de la piel como golpes, úlceras, quemaduras, etc.

En el Museo de Zaragoza se conservan algunas de estas piezas que contienen en su interior restos de aceite vegetal perfumado de romero y perfume tipo ceratum refrigerans. Las técnicas arqueométricas para conocer los materiales orgánicos utilizados en la antigüedad para la obtención de cosméticos y medicinas están siendo aplicadas por la Dra. Josefina Pérez Arantegui (Instituto Universitario de investigación en Ciencias ambientales de Aragón. Universidad de Zaragoza) en diversos tipos de contenedores como ungüentarios o útiles de tocador, habiendo sido publicados algunos de los resultados (Pérez Arantegui et alii, 1996, 649-655 y Beltrán Lloris, 2007, 769-780).

Los perfumes o ungüentarios realizados por maestros artesanos que constituían los colegia ungüentaria estaban realizados, por tanto, con base oleosa y no alcohólica y requerían un contenedor muy específico que garantizara la estabilidad química de la mezcla, que retrasara o impidiera las reacciones químicas que perjudicasen el valioso perfume que se extraía de plantas raras o que procedía de lejanas tierras de Oriente (Palop Fernández, 2007 y Alonso Cereza, 2010).

La importancia que alcanzaron los perfumes queda reflejado en algunos testimonios literarios, pudiendo citar los de Marcial, recogidos por Alonso Cerezo: "Nunca le dejes a tu heredero ni perfumes ni vinos. Que se quede él el dinero; todo eso dátelo a ti" (Epigramas, Libro XIII, 126); "Como la hermosa Filis se me había entregado sin reparos una noche entera de todas las maneras, y

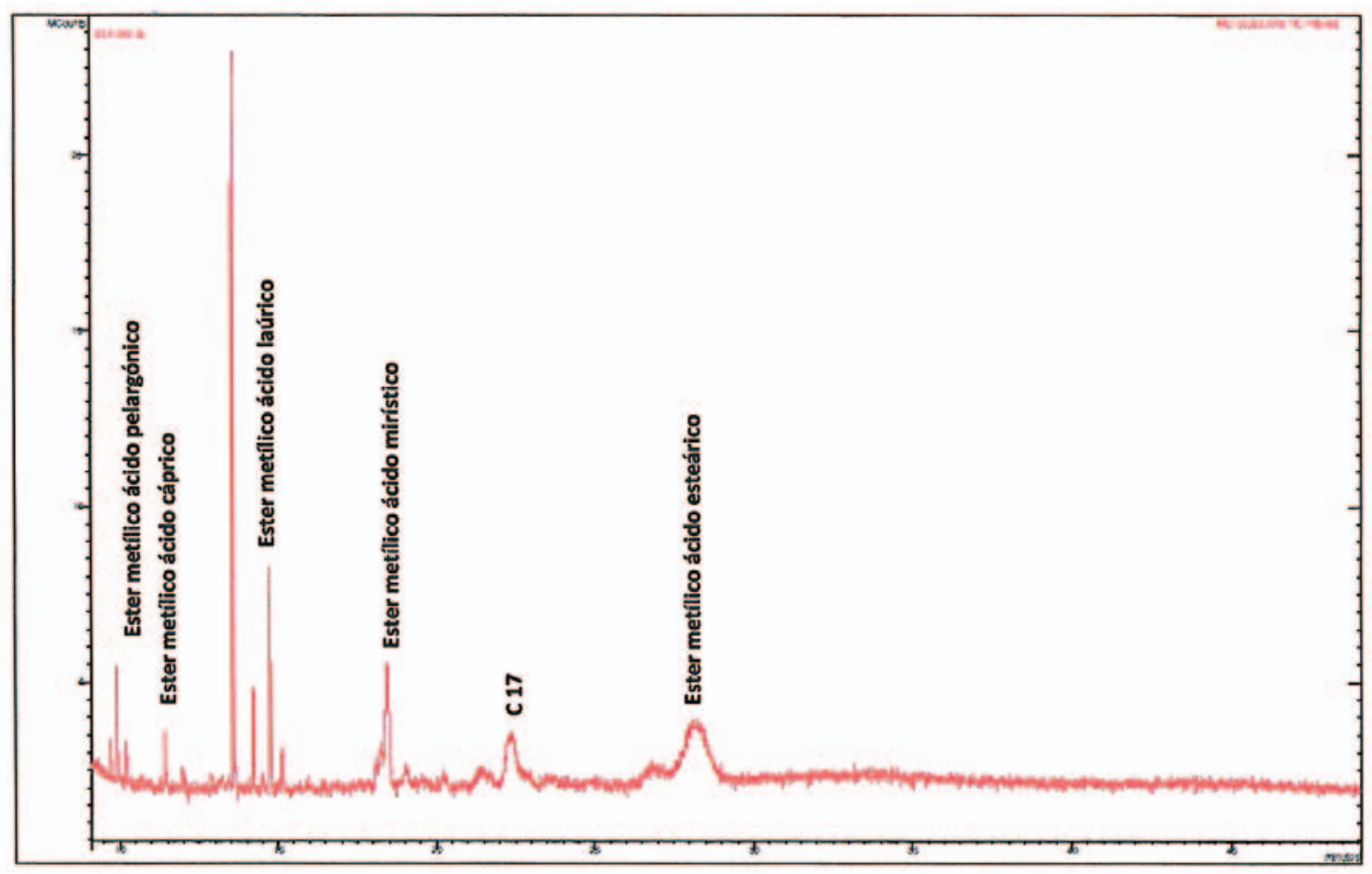

Figura 1: Cromatograma del contenido del ungüentario altoimperial que se recoge en la fig.9. 
a la mañana siguiente andaba yo pensando qué regalo le haría, si una libra de perfume Cosmo o de Naceros" (Epigramas, Libro XII, 65) (Alonso Cereza. 2010).

Lo curioso de esta pieza es el lugar en el que fue encontrado, junto a una acumulación de monedas bajoimperiales, fechadas entre el 270 y el 395. Se trata de un tesorillo de 96 monedas de bronce y una de plata encontradas bajo el derrumbe del tejado que cubría el corredor del peristilo. Las monedas se acuñaron en Lugdunum, Arelate, Aquileia, Roma, Siscia, Tesalónica y Alejandría, bajo los emperadores: Claudio II, Diocleciano, Constancio I, Constancio II, Juliano II, Valentiniano II, Teodosio, Magno Máximo, Arcadio y Honorio. Por tanto, se formó una selección voluntaria de unas monedas de alto valor, ya que el $90 \%$ son Ae2, una moneda que, a partir de la reforma de Graciano se alzará como una pieza fuerte (Cabello Briones, 2008).

La presencia de esta pieza altoimperial en un contexto tardío lo podemos explicar, tal y como nos ha sugerido el Dr. Fuentes, para su reciclado, una práctica muy frecuente en época bajoimperial. El vidrio no es un material tan universalmente conseguible, ya que requiere de ciertos componentes que no son asequibles en cualquier lugar. Cuando el vidrio se refunde pierde ciertas calidades, pero pueden ser suplidas de otra forma: la dureza añadiendo más cal; depurando las espumas con precipitaciones, decolorando la mezcla que enturbia el color o buscando reacciones que anulen ciertas oxidaciones de componentes metálicos; el vidrio viejo, pues, tiene muchas ventajas y no pocos inconvenientes. Por un lado necesitaba una menor temperatura de fusión, hacia los $525-550^{\circ}$ C., por otro, la pasta se embrutecía y había que refinarla (Fuentes Domínguez, 2001,147).

Este fragmento no es la única pieza altoimperial, ni tampoco el único ungüentario documentado en el yacimiento, ya que en las campañas desarrolladas en 1986, 1995, 1996, 1999 y 2000 se han hallado otros ejemplares fechados entre el siglo I y II d.C., identificados como copas, cuencos, tapaderas, piezas, todas ellas, que proceden de un basurero que se documentó junto a la cabecera de la basílica cristiana (Torrecilla Aznar, 2000, 384).

\section{EL VIDRIO BAJOIMPERIAL.}

Conocemos que a partir del siglo III d.C., la industria del vidrio sufrió una serie de cambios. Lo que se sopla es un vidrio muy reiterativo, multirrepetido, adaptado al consumo local. Se sopla lo que se pide y hay poca variedad (Fuentes, 2007,17).

Los recipientes utilizados habitualmente en el servicio de mesa reducen su número, mostrando gran uniformidad en técnica. El vidrio fue un magnífico material para conservar alimentos y bebidas sin alterar los sabores; por ser transparente, permitía reconocer su contenido), por ser fácil de limpiar y por poder volverse a usarse mediante el reciclado.

A partir del siglo IV d.C. predominarán las formas para beber o para contener vino (vasos, botellas y jarras) así como los cuencos, que también podían tener la misma funcionalidad, siendo éste el tipo más usual que hemos podido documentar en El Saucedo, tal y como veremos a lo largo de estas líneas. Los cuencos presentaran formas básicas: semiesféricas, troncocónicas, pero no habrá dos iguales. También se documentarán algunos platos y fuentes. Parece que el vidrio se usó en muchísima menor medida que en las etapas anteriores.

El vidrio Bajoimperial, en líneas generales, es soplado, con coloración verde-amarillenta u oliva, y decoraciones complejas. También se constata una baja calidad del producto, elaborado en diversos talleres locales, centrados en la producción de recipientes para uso cotidiano (Sánchez de Prado, 2004,93). En época Bajoimperial, además de los talleres de vidrio situados en la periferia industrial de las ciudades y del vidrio importado de Italia, Oriente y África, se constata la existencia de sopladores ambulantes que se repartían territorios muy amplios que visitaban en ciclos de larga duración, probablemente anuales, tal y como señala el Dr. Fuentes. Llegaban en fechas esperadas por los vecinos, recogían el material fragmentado que cambiaban por baratijas o por complementos domésticos y se vuelve a soplar en talleres alquilados, vendiéndose esta producción in-situ. Surtían las poblaciones rurales: aldeas, vici y villas y población diseminada (Fuentes, 2007,17). 
Generalmente, predominan en esta villa de El Saucedo los vidrios de aspecto translúcido y transparente, siendo menos frecuentes los vidrios opacos que aparecen sobre todo para fabricar algunos materiales constructivos como las teselas o en algunos elementos de adorno personal. El vidrio documentado en estas campañas en la villa de El Saucedo presenta una coloración predominante en tonos verde. La presencia predominante de vidrios con diferentes tonalidades de color verde se explica por la existencia de pequeñas cantidades de hierro en la composición química de estas piezas. Se señala que la coloración verdosa es característica del vidrio reciclado y mezclado, ya que este se caracteriza por la aparición de impurezas que rebajaban la categoría del vidrio (Fuentes Domínguez, 2001,148). En algunos casos los fragmentos hallados presentan una doble tonalidad. Una parte de la pieza es de color verde o amarillo, siendo el resto de aspecto incoloro.

Son poco frecuentes los vidrios que presentan un color azul, obtenido con óxido de cobre; así como los de color ligeramente amarillo, en concreto un par de fragmentos: 2003.31 (SECYR $335)$ y 2006.35 , obtenidos con la mezcla de cobre y azufre.

Los vidrios de aspecto esmerilado y los fragmentos de vidrios incoloros están poco documentados en las excavaciones arqueológicas realizadas en el yacimiento en los últimos años. Es frecuente la aparición en el asentamiento de vidrios con decoración de molduras en relieve, una técnica característica del Bajoimperio y tardoantigüedad. Otro motivo decorativo presente en El Saucedo es una decoración de nido de abeja en relieve. Este tipo de decoración ya se había documentado en el yacimiento en campañas anteriores al año 2000, concretamente en dos (20.202 y 20.228) (Torrecilla Aznar, 2000, 383). Las tres piezas son muy semejantes a una pieza hallada en Conimbriga de color verde esmeralda realizado a molde y datado en el siglo IV d.C., al igual que nuestros ejemplares. Los recipientes fabricados a molde aparecen como elementos relictos en los depósitos tardoantiguos (Uscatescu, 2004,34).

En cuanto a la técnica de fabricación destaca el soplado, la presencia de burbujas en la mayoría de las piezas que aquí presentamos suelen alinearse a lo largo de las líneas de soplado. Su presencia es muy común en los vidrios tardíos, produciéndose debido a la temperatura de fusión alcanzada: 1300 o $1500^{\circ} \mathrm{C}$., temperatura insuficiente para la correcta fabricación, ya que no se logran expulsar totalmente los gases de reacción (Torrecilla Aznar, 2004,335).

A pesar de la fragmentación de la mayor parte de las piezas de vidrio halladas en el yacimiento podemos distinguir entre las piezas más documentadas pequeños cuencos (Tipo I de Fuentes) hemisféricos con paredes de escaso grosor, copas y jarras (tipo III de Fuentes). Se trata de piezas habituales en la vajilla romana de mesa de este periodo y suponen en general una evolución de los tipos ya existentes en época altoimperial. Los cuencos (poculi) se caracterizan por ser recipientes ápodos o no cuya anchura es superior a la altura. Tuvieron un uso polivalente y estuvieron destinados a contener bebidas o alimentos. Existió una gran variedad de formas de cuencos y en la península ibérica aparecen con frecuencia, se trata como hemos dicho, de un recipiente de uso cotidiano y se documentan en cantidades lo suficientemente importantes como para hacernos pensar en la existencia de talleres no solo en el ámbito peninsular sino también de carácter local. La mayoría de los paralelos encontrados aparecen dentro del ámbito peninsular aunque esta forma no es desconocida en algunos puntos del mediterráneo o incluso en yacimientos centroeuropeos, teniendo en cuenta la importancia de los talleres de la zona renana con Colonia a la cabeza, si bien es cierto que en estos últimos lo hacen con escasa frecuencia. Se documentan en Alconectar (IV-V d.C.); Baetulo, Lucentum (IV-V d.C.); Tarraco (Primera mitad del siglo V d.C.), Necrópolis de La Morterona (Saldaña, Palencia) (Rodríguez Ibáñez, 2007). Contenían productos semisólidos o salsas, siendo de uso individual o colectivo (Ortiz Palomar, 2001, 84).

En cuanto a las copas de época bajoimperial se caracterizan por ser recipientes con pie, ya lleven vástago o apoyen sobre una base. Las piezas documentadas en el yacimiento conservan fragmentos de la base y del umbo central. Se trata de un tipo de copa que aparece frecuentemente en las regiones del limes y en la Galia en contextos arqueológicos de los siglos IV-V d.C. 
Es interesante destacar también el hallazgo, de un fragmento del cuello de una jarra. El repertorio de jarras de vidrio con un asa, es enorme, en cantidad, variedad y decoración, sin embargo, apenas hay jarras de cerámica en el mundo romano; hay otras cosas como botellas, orzas, etc... Por tanto, podemos decir que la mesa romana se surtió de jarras de vidrio (Fuentes, 2007-29).

Para concluir con la vajilla de mesa, debemos mencionar, entre los materiales documentados en El Saucedo dos asas. Las asas de los siglos III y IV d.C. se caracterizan, en términos generales, por ser flexibles y con múltiples pliegues, describiendo marcadas curvas y ondulaciones, en muchos casos tienen un carácter muy oriental. Estas características contrastan con las que presentan las asas de época altoimperial que son poco variadas, simples y predominan en ellas la línea recta y las composiciones geométricas. Son sólidas y poseen más masa vítrea y menos filigrana (Germán Rodríguez y Alonso Cereza, 2005, 213).

Dentro de las piezas de adorno personal hallados en el yacimiento podemos destacar tres cuentas, una con decoración en zig-zag (2003.8/ SECYR352) y líneas paralelas en los extremos (Fig. 2). La pieza 2003.11 (SECYR348) es circu-

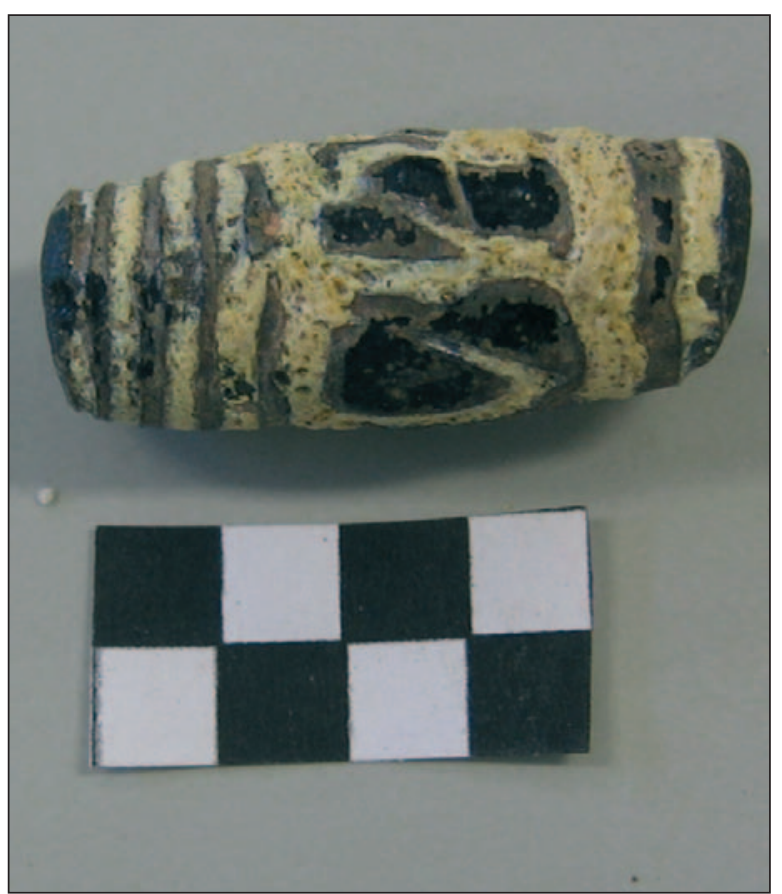

Figura 2: Imagen de la cuenta bajoimperial con decoración en blanco y negro. lar de tonos crema-anaranjado. Presenta un orificio central de $1 \mathrm{~cm}$. de diámetro. La tercera cuenta documentada (2006.4/ SECYR), es de color verde opaca con pequeñas perforaciones en los extremos y tiene una decoración de líneas paralelas en los extremos y en el centro, presentando una decoración con una trama de pequeños rombos (Fig. 3). En las campañas anteriores practicadas en El Saucedo se documentó otra cuenta de collar (20.500) de forma circular y realizada en color azul cobalto oscuro (Torrecilla Aznar, 2004, 333).

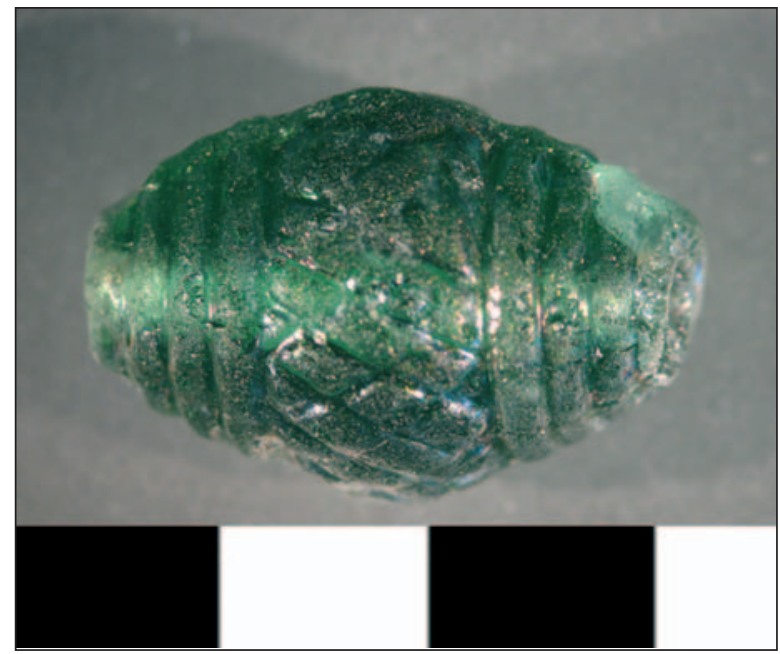

Figura 3: Imagen de la cuenta bajomiperial de color verde con decoración retícula de rombos.

Entre los primeros usos del vidrio está el adorno personal y dentro de este, los abalorios que fueron las creaciones más antiguas, su objetivo: hacer más asequibles los adornos. En época romana, las cuentas de collar fueron un sustitutivo de las piedras preciosas y semipreciosas a las que pretendían imitar y que eran más caras y difíciles de conseguir. Tanto por su brillo como por tratarse de un compuesto que se podía colorear a voluntad, el vidrio se convirtió en el material ideal para producir tan codiciosos minerales de forma más barata. La mayor dificultad radicaba en conseguir el matiz exacto de color.

Dada su amplia difusión, así como la larga subsistencia de una serie de modelos, resulta imposible determinar su cronología y procedencia, en función de la morfología y las técnicas formativas y decorativas empleadas en su fabricación (Madariaga García, 2004-216). No 
obstante, podemos señalar que la ciudad de Alejandría fue uno de los principales centros en la elaboración y venta de cuentas de vidrio (Falomir Ventura, 2005, 125-144)

También es interesante destacar el hallazgo de un fragmento de una pulsera de vidrio (2004.10/ SECYR336) de color negro opaco y sección semicircular. En las campañas desarrolladas en los años anteriores se documentaron otros fragmentos de pulsera: 20.001 , de vidrio negro y sección hemisférica; 20.211 decorada con incisiones transversales y paralelas; 20265 y 20502 de sección aplanada con rehundimiento central que define dos partes longitudinales, una de ellas más gruesa que la otra (Torrecilla Aznar, 2000, 379 y Torrecilla Aznar, 2004, 333). El vidrio negro se obtenía con la mezcla de cobre o hierro y manganeso.

Este tipo de pulsera se realizaba a partir de un cilindro anillado. La ornamentación se llevaba a cabo mediante herramientas que al pellizcar el vidrio en estado dúctil, daba como resultado una serie de costillas o acanaladuras paralelas en toda su cara exterior. La mayor parte de los ornatos que se confeccionan en vidrio negro opaco o en tonos oscuros habrían sido un intento de copiar el azabache, material elegante y en boga en época tardorromana, pero muy frágil del que tenemos algunos ejemplos de cuentas procedentes de la villa de Veranes (Gijón) o de la necrópolis de Albalate de Las Nogueras (Cuenca) (Fernández Ochoa et alii, 2005-2006, 137-194).

Las pulseras de vidrio fueron adornos personales baratos, que contaron con un doble significado: apotropaico y ornamental. El gusto por los brazaletes pasó de gentes orientales a griegos, etruscos y romanos. Los ejemplares documentados suelen tener un reducido diámetro, por lo que se ha llegado a pensar que debieron ser elementos de uso infantil y femenino, aunque en menor proporción también fueron objeto de adorno masculino. Además de documentarse en contextos bajoimperiales, época de mayor proliferación, piezas semejantes se encuentran en niveles altoimperiales de Astorga y en contextos islámicos, cristianos o judíos. Piezas semejantes se han hallado en un amplio territorio que incluye desde el Norte de África hasta el norte de España, donde podemos destacar cuatro ejemplares procedentes de Mentesa Oretana (Villanueva de la Fuente, Ciudad Real). Tres de estos ejemplares son completamente negros y otra es bicolor con un cordón metálico plateado pintado y enroscado sobre fondo azul (Benitez de Lugo y Álvarez García, 2002).

Pulseras similares a ésta realizada en vidrio negro de sección hemiesférica se han documentado en el solar de la plaza de la Morería (Sagunto, Valencia), fechadas en los ss. III y IV d.C. (Falomir Ventura, 2005, 125-144) y la necrópolis oeste de Complutum. El ejemplar conserva las estrías de la técnica de fabricación (por estiramiento de masa de vidrio caliente) y presenta alguna malformación por la deficiente manipulación del vidriero que la realizó (VVAA, 1998,255).

Todos estos elementos de adorno personal (pulseras de vidrio, cuentas de collar, etc) documentados en la villa de El Saucedo son también frecuentes en necrópolis peninsulares de los siglos IV-V d.C.

Dentro del material constructivo de época tardoantigua podemos incluir varios vidrios de ventana (2004.12/ SECYR 338). En el transcurso de las excavaciones anteriores se hallaron otros vidrios de ventana de color verde esmeralda; de color verde amarillento; incoloros y traslúcidos (Torrecilla Aznar, 2000, 380 y Torrecilla Aznar, 2004, 334).

A finales de la república y comienzos del imperio, la construcción de viviendas privadas y termas públicas se hizo cada vez más lujosa y diáfana, buscando en lo posible disfrutar de una iluminación natural durante las horas diurnas. Para estar a la moda que reclamaban los clientes, que exigía disponer de espacios abiertos y soleados, los arquitectos e ingenieros comenzaron a abrir en los muros de termas y otros edificios monumentales, amplios ventanales que se revistieron con materiales transparentes, que si, por un lado, dejaban pasar la luz solar y permitían ver el exterior a través de ellos, por otro debían aislar y proteger del frío y de la lluvia exterior. Las termas constituyeron el principal escenario de la gran transformación, de manera que además de lograr una iluminación natural, agradable y desprovista de humos, se lograba caldear parcialmente las salas, 
ahorrando parte de la leña que se precisaba para calentar estas salas.

Así pues, lo largo de los siglos, el vidrio ha sido el principal material utilizado como cerramiento de vanos de edificios de muy diversa índole. Su uso en toda variedad de tamaños, colores y formas, en construcciones tanto paganas como religiosas, se vio facilitado por una serie de características inherentes a este material, características que han sufrido pocos cambios con el paso de los siglos. En la construcción, sus principales ventajas, sobre otros materiales fueron sus propiedades de traslucidez y transparencia, aislamiento térmico y acústico y relativo bajo costo de la producción (Cortes Pizano, 2001).

Entre el material constructivo o arquitectónico aportado por la villa tardorromana de El Saucedo se incluirían también algunas teselas opacas de color verde (2004.6 y 2005.7). Teselas de vidrio ya fueron encontradas en campañas arqueológicas anteriores (Torrecilla Aznar, 2000, 380 y Torrecilla Aznar, 2004, 334). Este tipo de vidrio opaco, puede definirse como un vidrio de dos fases: la primera es la matiz vítrea y la segunda es, en general, una suspensión de cristales pequeños que difundiendo y absorbiendo la luz confieren al vidrio su opacidad. No es correcto, por tanto, referirse a las teselas de vidrio opaco como teselas de pasta vítrea (Ortiz Palomar, 2001, 55). La aplicación del vidrio en los mosaicos fue una técnica desarrollada en Mesopotamia en el III milenio a.C. y se trasmitió a Egipto, Grecia y Roma, donde su uso se hizo habitual a partir del siglo I a.C. como decoración arquitectónica de lujo ya que resultaba muy costoso y se combinaban con teselas de piedra para obtener un abanico cromático de calidad espectacular.

En ocasiones, la presencia de teselas de vidrio en algunos talleres obedece a una recuperación de las mismas para ser refundidas y reutilizadas en la ejecución de ornamentaciones de vidrio opaco sobre algunos recipientes. Este reciclaje resultaba particularmente ventajoso debido a que los vidrios opacos eran costosos y difíciles de fabricar (Ortiz Palomar, 2001, 55). La pieza de color blanco verdoso documentada en El Saucedo, imitaba un mármol blanco verdoso conocido como marmor carystim o mármol cipollino. Se puede, por tanto, señalar, que en algunas ocasiones se utilizaron vidrios planos opacos y coloreados, con un veteado muy decorativo, que fueron empleados como un sustituto de mármoles de gran lujo y alto precio (González Tascón, 2002,51).

\section{VIDRIO TARDOANTIGUO.}

En época tardoantigua debió producirse el vidrio según el modelo vigente desde el Bajo imperio; es decir, centros productivos localizados en las cercanías de las principales ciudades para el abastecimiento urbano y regional, junto a una red de pequeños sopladores ambulantes, diseminados por toda la geografía del territorio para atender a la población más aislada. En un artículo publicado en prensa diaria (ABC viernes 22 de julio de 2005), sobre las excavaciones que se llevan a cabo en el solar de La Encarnación (Sevilla) y que dirige el profesor F. Amores, se señala que se ha documentado, entre otros hallazgos, un taller de vidrio fechado en el siglo V d.C. Los artesanos ambulantes, aniversari vicini, subidos a un carro apenas necesitaban más que sus manos, sus conocimientos y un pequeño arsenal de colorantes, decolorantes, rectificadores, y un instrumental muy sencillo para ejercitar su trabajo por periodos cortos de tiempo y siguiendo un recorrido prefijado y siempre el mismo. El soplador ambulante llegaba a cualquier pueblo donde ya conoce a todas las personas que necesitan y donde es conocido por la población; tras instalarse en un taller alquilado (el taller de un ceramista o entejar que una parte del año no podían trabajar). Con material de desecho construía un par de pequeños hornos contiguos, quizá uno sobre el otro para ahorrar calorías y espacio.

Conocida su estancia en la comarca comenzaría a recoger el vidrio roto o amortizado de todas las casas que había sido cuidadosamente guardado para su trueque por otros productos y por nuevo vidrio soplado. Conseguida una cantidad suficiente se procede al lavado y fundido de este vidrio roto, cosa que se consigue con cierta facilidad y a baja temperatura. En ese momento el vidriero ya sabe qué clase de frita le va a salir y puede añadirle los correctores necesarios para conseguir un aspecto y propiedades lo más parecidas al vidrio normal, de composición equilibrada y buena calidad. Conseguida la pasta el 
vidriero soplaría lo que se le había solicitado, lo que ha sondeado que puede vender, una producción destinada a ser vendida directamente, elaborada casi por encargo.

Este modelo se adaptó a la nueva realidad territorial y poblacional tardoantigua y visigoda y preludiará el modelo de artesanos y profesionales medievales en las ferias y mercados de las ciudades más importantes y en las que, por supuesto, no faltaban los vidrieros (Fuentes, 2007-23).

En esta etapa aparecen formas nuevas, entre las que tenemos que mencionar un tipo de copa, documentada en El Saucedo, que se caracteriza por presenta un perfil triangular sobre pie alto de caña y amplio repié de disco. La forma es esbelta y elegante, aunque la mayoría de las veces, su factura es más bien tosca y nunca del todo simétrica. La técnica de fabricación no era del todo fácil, pues hay que elaborar piezas a molde, estirarlas y soldarlas hechas por separado; algo complicado en un mundo de fabricación ramplona, rápida y sumaria. Es una forma conocida en otras partes del mediterráneo, tanto en Galia como en Centroeuropa y Norte de África, no se sabe cómo llegó a Hispania. La diferencia entre las fabricadas en Hispania y en otras zonas del mediterráneo estriba en que en las hispanas son macizas al igual que la galleta del repié (Fuentes, 2007, 28) mientras que las halladas en otros contextos la caña del pie es hueca, al haber sido fabricada mediante soplado.

La pieza (2003.2) presenta un vástago de sección ovalada y una base de aspecto circular rehundida hacia arriba. La cronología de este pie de copa de vidrio podría fijarse entre los siglos VIVII d.C. y su forma tiene bastante similitud con la parte inferior de una copa de vidrio azul en forma de piña documentada en la necrópolis tardorromana de Carteia.

Por último es interesante destacar la presencia de algunos restos de producción de vidrio, quizá desechados por un vidriero itinerante que pudo trabajar durante un tiempo en la villa aprovechando la infraestructura, espacio, hornos y combustible disponible (Torrecilla Aznar, 2004, 335).

\section{ESTUDIO ARQUEOMÉTRICO DE LOS VIDRIOS}

Para realizar este estudio de los vidrios de El Saucedo, hemos hecho una corta selección de muestras de algunas piezas, y que han sido referidas en líneas anteriores con la sigla y número dado en el Lab. SECYR ${ }^{n}$ ). Estas muestras creemos que son representativas de las fases documentadas en la ocupación de la villa.

El conocimiento de la composición química de un vidrio se puede utilizar como herramienta de datación relativa de la etapa histórica o tecnológica de producción y uso, ya que sus componentes principales brindan información sobre los ingredientes con los que pudieron ser fabricados dichos materiales, y éstos a su vez ser adscritos a un momento o etapa histórica concreta (Gutiérrez 2009:127-152).

Según los relatos antiguos de fuentes antiguas bien conocidas, el vidrio artificial se obtenía fundiendo una mezcla de tres ingredientes: arena o guijarros de cuarzo aplastados, un agente fundente que puede ser natrón (compuesto por bicarbonato y carbonato de sodio hidratado, $\left.\mathrm{Na}_{2} \mathrm{CO}_{3} \cdot \mathrm{HNaCO}_{3} \cdot 2 \mathrm{H}_{2} \mathrm{O}\right)$ o cenizas de plantas y cal $(\mathrm{CaO})$.

El componente principal de la arena, esto es, el $\mathrm{SiO}_{2}$ cumple la función de darle estabilidad al material resultante, es el componente mayoritario del vidrio y se conoce como vitrificante. El fundente disminuye el punto de fusión de la mezcla y alarga el tiempo de maleabilidad del vidrio y finalmente, la cal actúa como un estabilizante mejorando la estabilidad química del material.

Tanto los vidrios fabricados con natrón como aquellos hechos con cenizas de Salicornia, presentan un alto contenido de sodio, sin embargo difieren bastante en la cantidad de $\mathrm{K}_{2} \mathrm{O}$ y $\mathrm{MgO}$. Así, cuando un vidrio posee un porcentaje menor del $1.5 \%$ de cada uno de estos óxidos corresponde a un vidrio fabricado con natrón, mientras que contenidos mayores a ese valor se refieren a vidrios producidos con cenizas de Salicornia (Freestone, 2006: 201-210).

Dependiendo de las facilidades que haya podido tener una civilización antigua para acceder a los ingredientes base, a lo largo de los períodos de 
la historia, se han utilizado diferentes tipos de fundentes, estabilizantes y vitrificantes para la fabricación del vidrio.

Además, en ocasiones se utilizan algunos aditivos, sales u óxidos metálicos que se agregaban intencionalmente con el fin de cambiar las propiedades físicas del vidrio (color, opacidad), aunque la existencia de pequeñas cantidades de impurezas provenientes de las materias primas también influye en el aspecto del material resultante. El compuesto colorante más frecuente es el óxido de hierro (bajo la forma de iones $\mathrm{Fe}^{2+}$ otorga una coloración verde al vidrio), el cual se encuentra presente como la principal impureza de la arena. Además, algunos elementos de la primera serie de transición $(\mathrm{Mn}, \mathrm{Co}, \mathrm{y} \mathrm{Cu})$ se añadían en pequeñas cantidades (como derivados de minerales) para dar la coloración deseada al material.

Por otra parte, por medio de la recopilación de una gran cantidad de datos obtenidos de vidrios provenientes de diferentes localizaciones, Freestone (2005: 1-14) ha determinado cinco centros de producción primaria del vidrio
(WadiNatrum, Egipto II, Levantino I y II y HIMT (High Iron Manganese Titanium)) utilizando las composiciones de cal $(\mathrm{CaO})$ y la alumina $\left(\mathrm{Al}_{2} \mathrm{O}_{3}\right)$, como se muestra en la figura 4 .

En la época romana, el vidrio se fabricó a gran escala y se convirtió en un producto de consumo común, especialmente cuando se introdujeron las técnicas de soplado. El color, que inicialmente había tenido una fuerte importancia, perdió valor y se optó por la producción de vidrios incoloros utilizando la acción decolorante del óxido de antimonio $\left(\mathrm{Sb}_{2} \mathrm{O}_{5}\right)$ y de manganeso $\left(\mathrm{MnO}_{2}\right)$. También la fabricación a mayor escala pudo estar relacionada con la generalizada utilización de natrón en la producción de vidrios ya que este mineral además de conseguirse fácilmente, no necesitaba ninguna preparación especial.

Así, los vidrios en la época romana, muy homogéneos, se caracterizan por ser del tipo sódico-cálcicos, fabricados con arena y natrón, y la alúmina varía entre 2 y $3 \%$ para la mayoría de los vidrios romanos de los siglos I y III d. C.

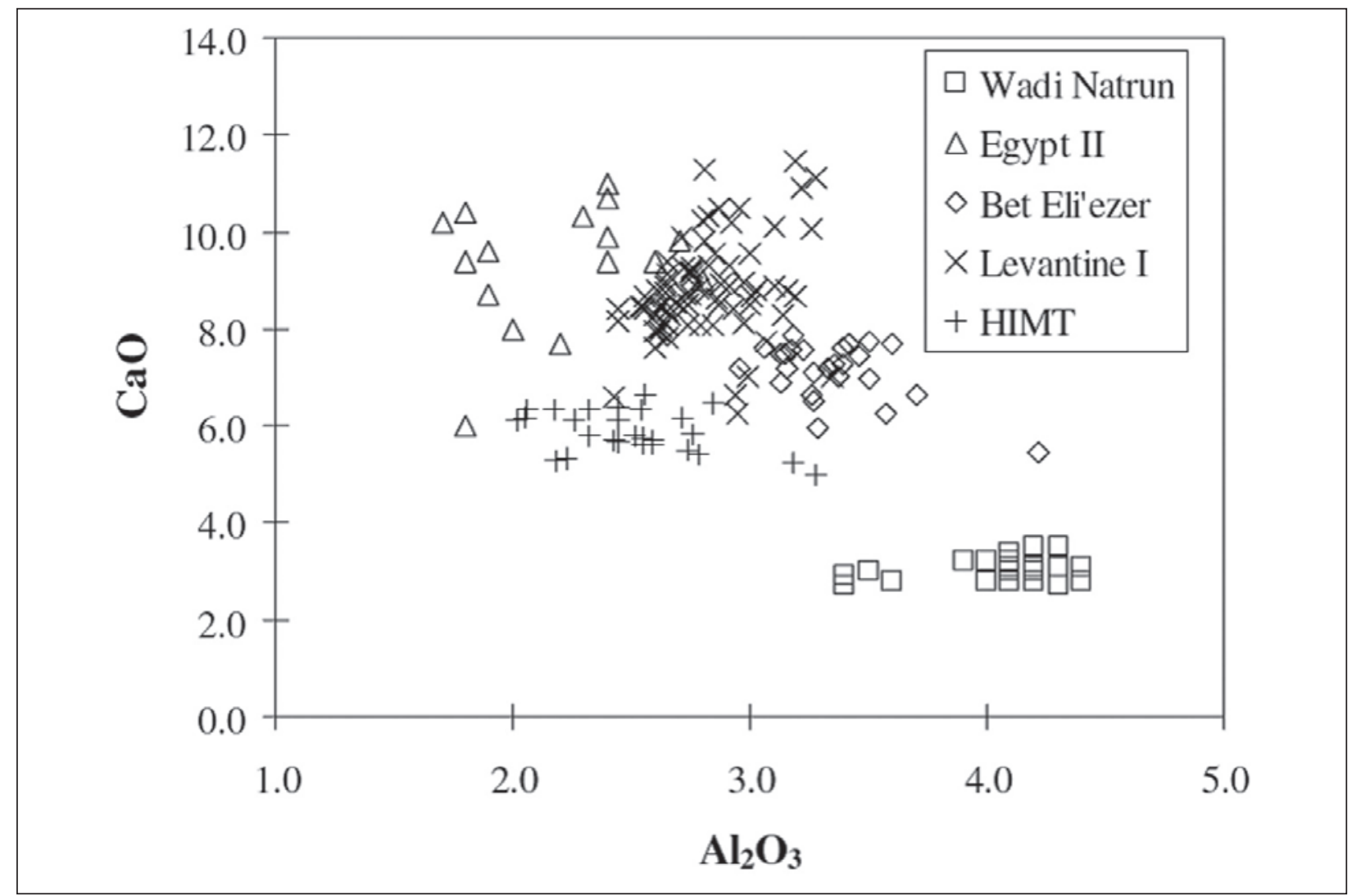

Figura 4: Porcentajes de $\mathrm{CaO}$ y $\mathrm{Al}_{2} \mathrm{O}_{3}$ para cinco grupos de producción encontrados en el Mediterráneo Oriental entre el siglo IV al V d. C publicados por Freestone (2005:1-14). Los datos se expresan en \% en peso. 


\section{Metodología UTIlizada: ANÁlisis DE VIDRIOS CON LA TÉCNICA SEM-EDX}

El microscopio electrónico de barrido (del inglés Scanning Electron Microscope) viene siendo utilizado en los últimos años como una herramienta habitual y asequible para el análisis de vidrios arqueológicos. En primer lugar porque permite la observación de los materiales a nivel superficial y además, cuando se adapta un detector por Dispersión de Energía de rayos X (SEM-EDX), hace posible también la cuantificación de la composición química por medio de la determinación de los rayos $\mathrm{X}$ característicos que emite la muestra como resultado de la irradiación con electrones.

Las medidas que se realizaron sobre los vidrios fueron llevadas a cabo en la Unidad de Microscopía del SIdI (Servicio Interdepartamental de Investigación). El equipo utilizado fue el Microscopio Electrónico de Barrido Philips XL30, acoplado al analizador EDAX DX4i.

Con el objetivo de distinguir entre la capa de corrosión que se produce como consecuencia de la interacción de la superficie del vidrio con el medioambiente y la matriz del vidrio, se han tomado muestras de unos pocos centímetros de los fragmentos. Dichas muestras han sido embutidas en una resina, pulidas con lijas de carburo de silicio ( $\mathrm{SiC}$ ) de diferente tamaño de grano y finalmente pulidas con alúmina.

En la figura 5 se muestra como ejemplo un espectro SEM-EDX obtenido para el fragmento de vidrio SECYR343 y en la figura 6 se presenta la Tabla 1 con la composición química de los vidrios analizados.

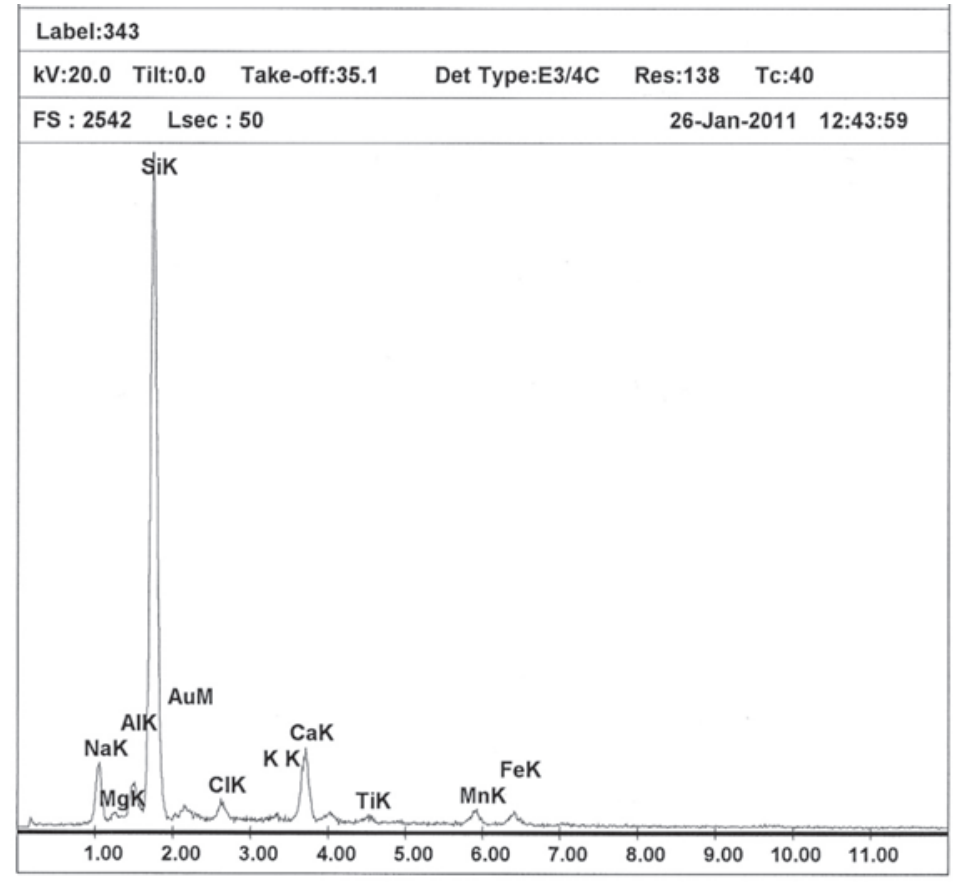

Figura 5: Espectro SEM-EDX del fragmento 2004.13 (SECYR343).

El eje de las abscisas representa la energía de rayos $\mathrm{X}$ en $\mathrm{KeV}$ y en el eje de las ordenadas se observa el número de cuentas.

\begin{tabular}{|c|c|c|c|c|c|c|c|c|c|c|c|}
\hline SECYR & color & $\mathrm{Na}_{2} \mathrm{O}$ & $\mathrm{MgO}$ & $\mathrm{Al}_{2} \mathrm{O}_{3}{ }^{*}$ & $\mathrm{SiO}_{2}$ & $\mathrm{Cl}$ & $\mathrm{K}_{2} \mathrm{O}$ & $\mathrm{CaO}$ & $\mathrm{Fe}_{2} \mathrm{O}_{3}$ & $\mathrm{TiO}_{2}$ & $\mathrm{MnO}$ \\
\hline 335 & incoloro & 16.83 & - & 4.37 & 71.94 & 1.02 & 0.42 & 4.89 & 0.52 & - & - \\
\hline 338 & verde & 17.4 & 1.67 & 5.16 & 68.53 & 0.87 & 0.26 & 3.55 & 0.89 & 0.32 & 1.34 \\
\hline 340 & verde & 16.78 & 1.49 & 3.83 & 70.7 & 0.97 & 0.35 & 3.56 & 1.17 & - & 1.14 \\
\hline 343 & verde & 17.44 & 1.88 & 5.06 & 67.25 & 0.87 & 0.30 & 4.27 & 1.21 & 0.53 & 1.18 \\
\hline 344 & verde & 17.33 & 1.48 & 4.68 & 68.11 & 0.78 & 0.44 & 4.43 & 1.24 & 0.35 & 1.17 \\
\hline 345 & incoloro & 17.93 & 1.04 & 3.91 & 70.93 & 1.06 & 0.33 & 4.32 & 0.31 & - & 0.15 \\
\hline 346 & verde & 17.09 & 1.57 & 4.32 & 69.74 & 0.93 & 0.35 & 3.92 & 0.71 & 0.44 & 0.93 \\
\hline 349 & verde & 17.32 & 1.68 & 4.27 & 69.75 & 1.08 & 0.34 & 4.37 & 0.42 & 0.77 & - \\
\hline
\end{tabular}

Figura 6: Tabla 1. Composición elemental obtenida con la técnica SEM-EDX. Las concentraciones de $\mathrm{P}_{2} \mathrm{O}_{5}, \mathrm{ZrO}_{2}, \mathrm{SO}_{3}, \mathrm{PbO}, \mathrm{SnO}_{2} \mathrm{y} \mathrm{Sb}_{2} \mathrm{O}_{3}$ se encuentran por debajo del límite de detección de la técnica. 


\section{DESCRIPCIÓN DE LOS VIDRIOS DEL ESTUDIO ARQUEOMÉTRICO}

Los ocho fragmentos analizados en el presente trabajo han sido recolectados en diferentes campañas de excavación realizadas entre los años 2003 al 2006. El grueso de los vidrios analizados pertenece a época Bajoimperial, que es también la de mayor abundancia de hallazgos, y por ello de muestras disponibles. En las figuras 7 a 14 pueden reconocerse las características de cada uno de ellos, que a continuación se detallan:

SECYR335: Saucedo'03, L4 UE111, 2003.31. Borde de un vaso o cuenco, se observan burbujas. Pertenece a la Época Bajoimperial (fig.7).

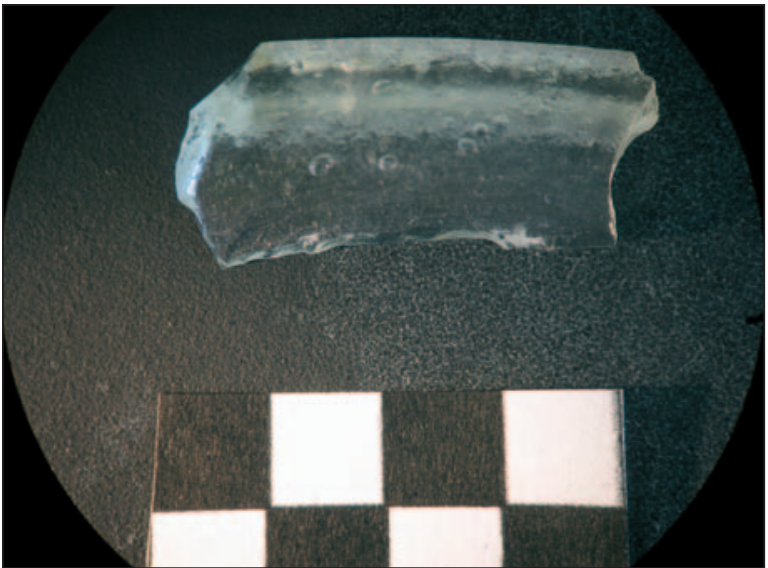

Figura 7: Imagen del posible borde de vaso o cuenco; pueden observarse un alto contenido en burbujas.

SECYR338: Saucedo'04, Q8 UE37, 2004.12. Vidrio de ventana con irisaciones violetas, superficie pulida, una cara lisa y la otra, algo rugosa. Dos fragmentos, uno traslucido y otro verde. Pertenece a la Época Bajoimperial (fig.8)

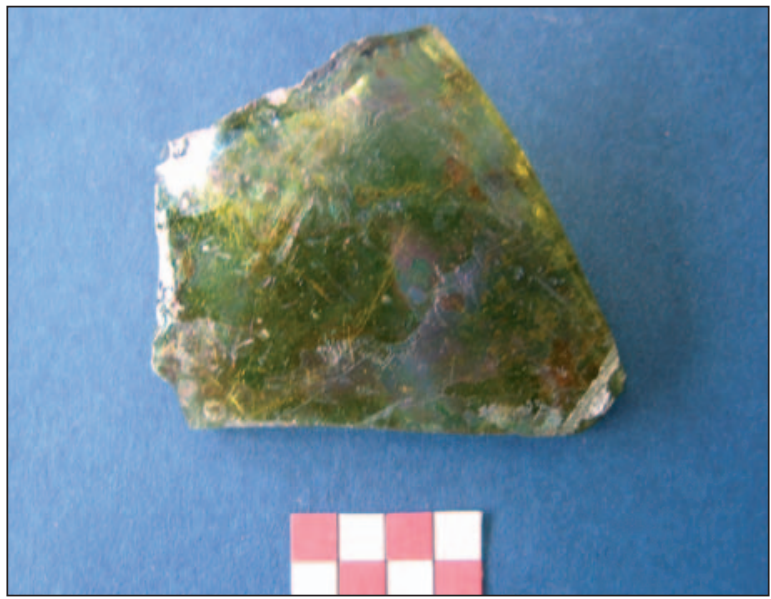

Figura 8: Imagen de posible? fragmento de vidrio de ventana de color verde; se percibe una película superficial de irisaciones típica de la alteración de vidrios arqueológicos.
SECYR340: Saucedo'04, C0 UE4, 2004.93. Base de un ungüientario de color verde. Pertenece a la Época Altoimperial. De esta pieza ya se han dado detalles del análisis cromatagráfico de los residuos de su interior en líneas precedentes (fig.9).

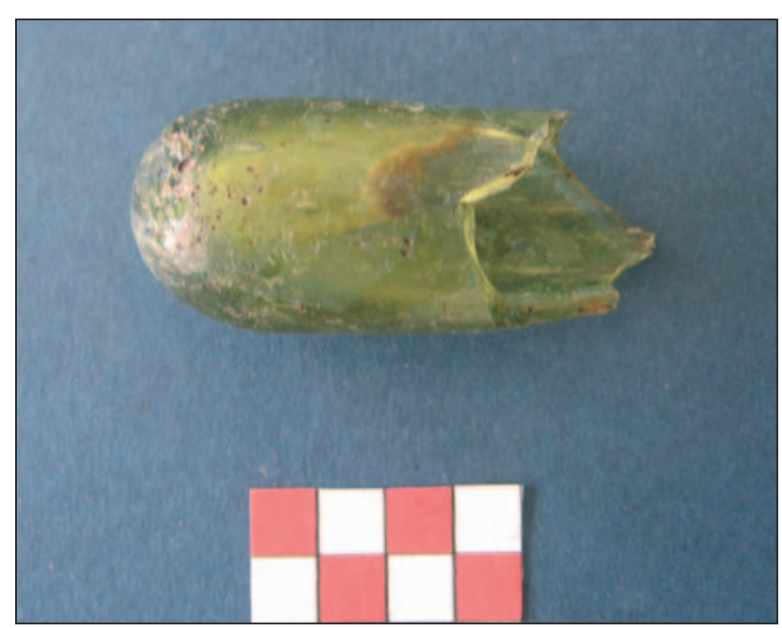

Figura 9: Imagen del ungüentario altomimperial, de coloración ligeramente verdosa, de cuyos residuo interior se realizó un análisis de cromatografía de gases recogido en la fig.1.

SECYR343: Saucedo'04, C0 UE4, 2004.13. Fragmento de pie de copa de vidrio color verde. Base rehundida hacia arriba, con umbo central. Pertenece a la Época Bajoimperial (fig. 10).

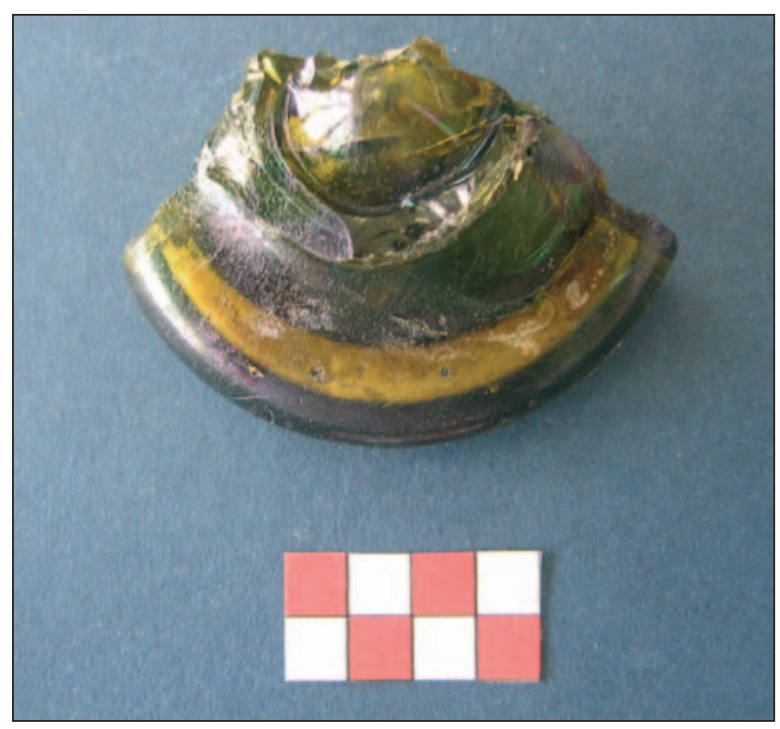

Figura 10: Imagen de fragmento de pie de copa de vidrio de color verde.

SECYR344: Saucedo'05, Q9 UE1, 2005.1. Fragmento de pequeña base de un cuenco de vidrio verde, no presenta burbujas. Pertenece a la Época Bajoimperial (fig.11). 


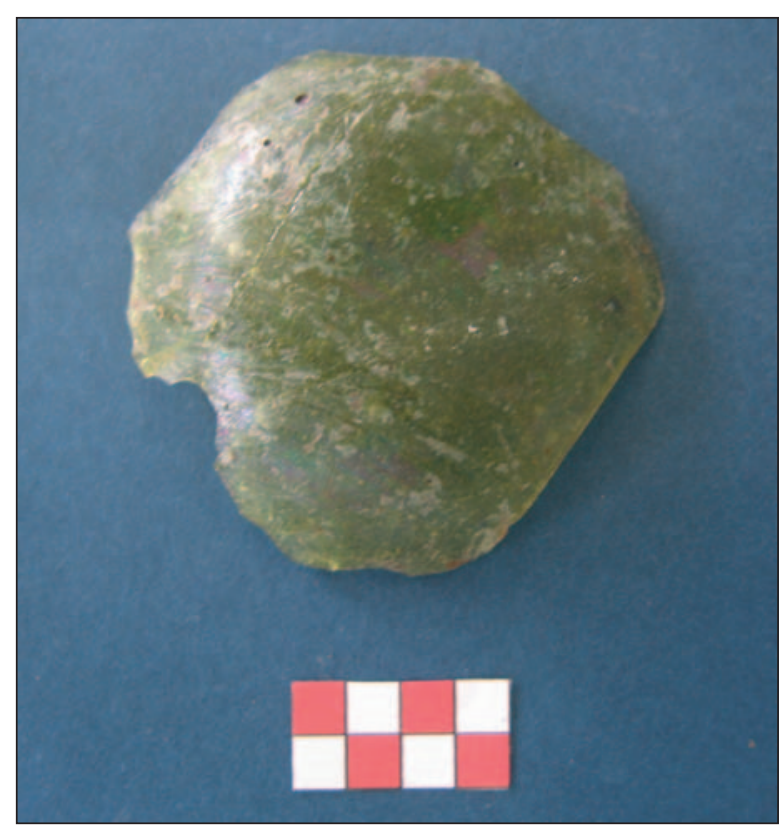

Figura 11: Imagen de pequeña base de un cuenco de vidrio de tono verde; presenta burbujas y una fuerte alteración superficial de áreas amplias.

SECYR345: Saucedo'04, Q8 UE1, 2004.38. Fragmento de vidrio opaco de aspecto plateado, posible fragmento de una base. Pertenece a la Época Bajoimperial (fig.12).

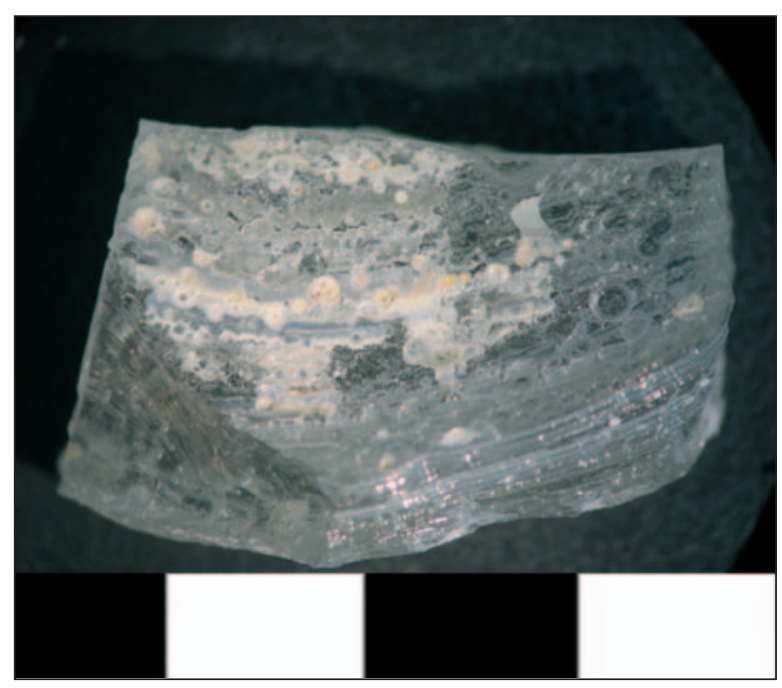

Figura 12: Imagen de fragmento de una base de vidrio transparente, que presenta una elevada cantidad de burbujas y una potente costra de alteración de las capas superficiales.

SECYR346: Saucedo'03, L4 UE 1, 2003.9. Fragmento de cuello de botella con estrías en su pared exterior, color verde claro transparente. Burbujas fusiformes u ovaladas. Pertenece a la Época Bajoimperial (fig.13).

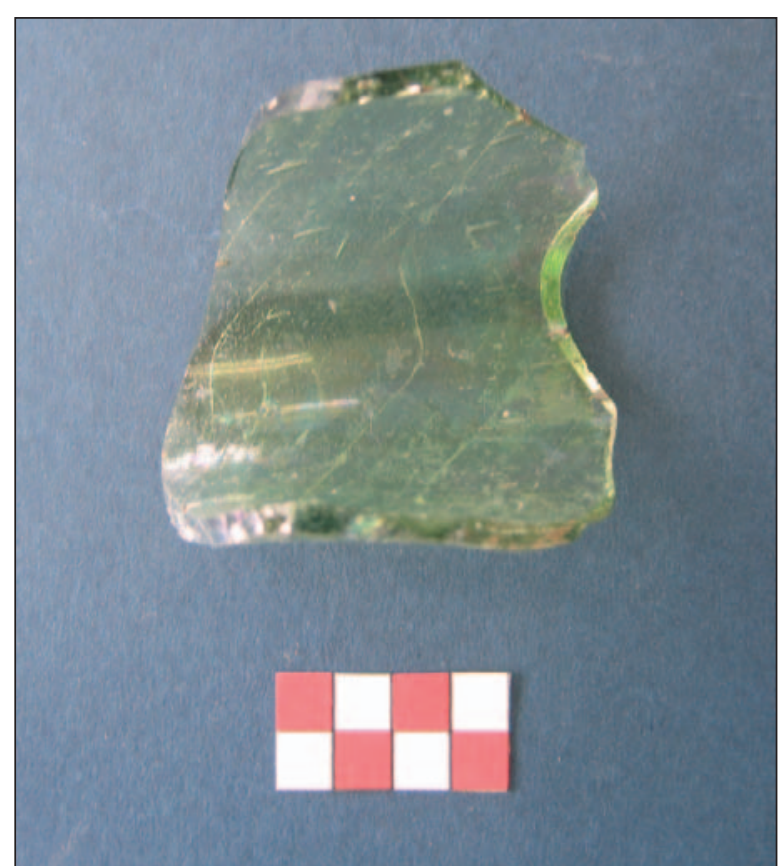

Figura 13: Imagen de un fragmento de cuello de botella de una leve coloración verdosa que muestra unas pequeñas estrías en superficie.

SECYR349: Saucedo'04, C0 UE1, 2004.63. Fragmento de vidrio de color verde, superficie lisa en una cara y rugosa en la otra, burbujas de diferentes tamaños de aspecto redondo. Pertenece a la Época Bajoimperial (fig.14).

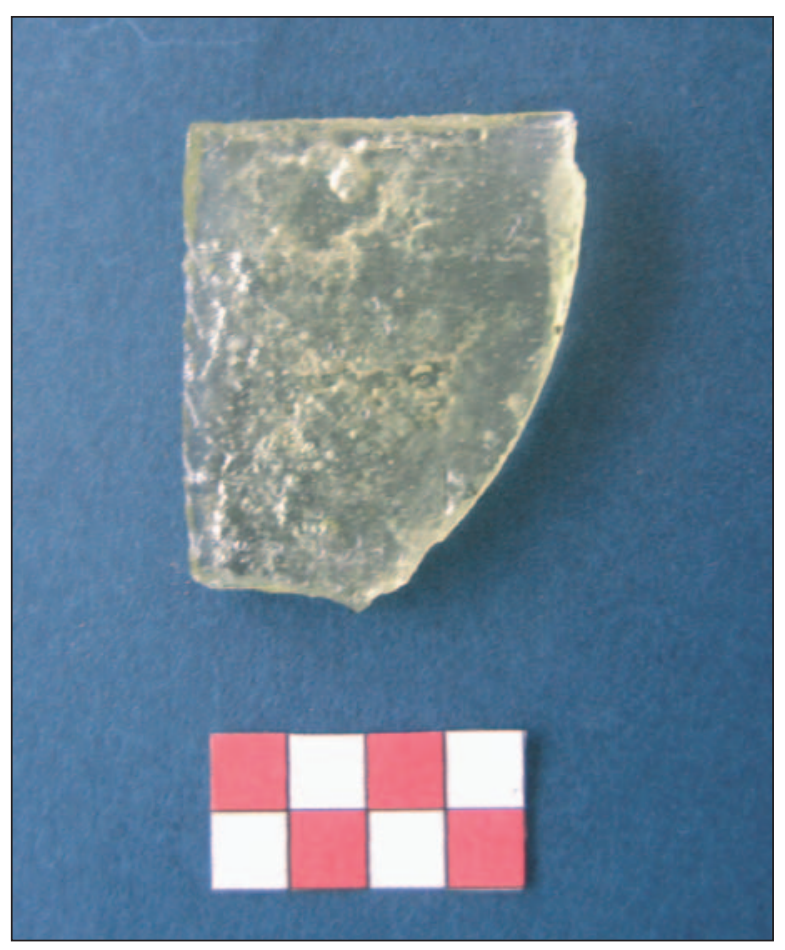

Figura 14: Imagen de fragmento de vidrio plano y liso por una de sus caras, de ligera coloración verde y elevada presencia de burbujas pequeñas y muy uniformes. 
EL DETERIORO DE LOS VIDRIOS DE EL Saucedo

Hemos incluido además una muestra (SECYR350), con el objetivo de realizar una evaluación del estado de conservación de estos vidrios, a consecuencia del deterioro desarrollado durante su enterramiento prolongado. Con ello queremos completar la investigación sobre el estado de conservación que se hizo hace algunos años con vidrios de esta villa de El Saucedo (Barrio 2002).

Los vidrios antiguos procedentes de yacimientos arqueológicos pueden sufrir un proceso de alteración superficial como consecuencia de las condiciones atmosféricas a las que han estado expuestos. La composición química de la superficie del material se puede modificar como resultado de la interacción del agua de lluvia o de la humedad ambiental con el vidrio.

Debido al intercambio con los iones $\mathrm{H}^{+}$del ambiente, los elementos alcalinos (sodio o pota- sio) del vidrio migran hacía el exterior del material. Como resultado, se forma una capa hidratada y una pérdida de $\mathrm{Na}$ y $\mathrm{K}$ en la superficie (Schreiner 2004 y Adriaens 2005), mecanismo conocido como lixiviación:

$$
\equiv \mathrm{Si}-\mathrm{O} \mathrm{Na}{ }^{+}+\mathrm{H}^{+} \rightarrow \equiv \mathrm{Si}-\mathrm{OH}+\mathrm{Na}^{+}
$$

Posteriormente, por la interacción con los componentes del ambiente como el dióxido de carbono $\left(\mathrm{CO}_{2}\right)$ o dióxido de azufre $\left(\mathrm{SO}_{2}\right)$, se forma en la superficie una "costra" de calcita $\left(\mathrm{CaCO}_{3}\right)$ o yeso $\left(\mathrm{CaSO}_{4} \cdot 2 \mathrm{H}_{2} \mathrm{O}\right)$. Aunque la corrosión del vidrio envuelve reacciones más complejas, en todos los casos se forma una capa superficial rica en grupos $\mathrm{OH}^{-}$con espesores en el rango de unos cuantos nanómetros hasta algunos cientos de micrómetros (Mäder et al..1998).

En la tabla de la figura 15 se muestra una comparación de los valores obtenidos para las diferentes capas de corrosión de la muestra SECYR350 según la imagen obtenida en SEM (fig. 16).

\begin{tabular}{|c|c|c|c|c|c|c|c|}
\hline Punto de análisis & $\mathrm{Na}_{2} \mathrm{O}$ & $\mathrm{MgO}$ & $\mathrm{Al}_{2} \mathrm{O}_{3}$ & $\mathrm{SiO}_{2}$ & $\mathrm{Cl}$ & $\mathrm{K}_{2} \mathrm{O}$ & $\mathrm{CaO}$ \\
\hline 1 & 1.29 & 2.04 & 12.53 & 79.75 & 0.3 & 0.37 & 3.73 \\
\hline 2 & 1.13 & 1.59 & 10.6 & 82.86 & 0.15 & 0.37 & 3.3 \\
\hline 3 & 1.43 & 1.48 & 3.89 & 87.14 & 1.29 & 0.22 & 4.55 \\
\hline 4 (matriz) & 15.58 & 0.2 & 3.02 & 76.52 & 0.92 & 0.10 & 3.67 \\
\hline
\end{tabular}

Figura 15: Tabla 2.

Composición elemental obtenida en las diferentes capas de corrosión según se muestra en la imagen con SEM

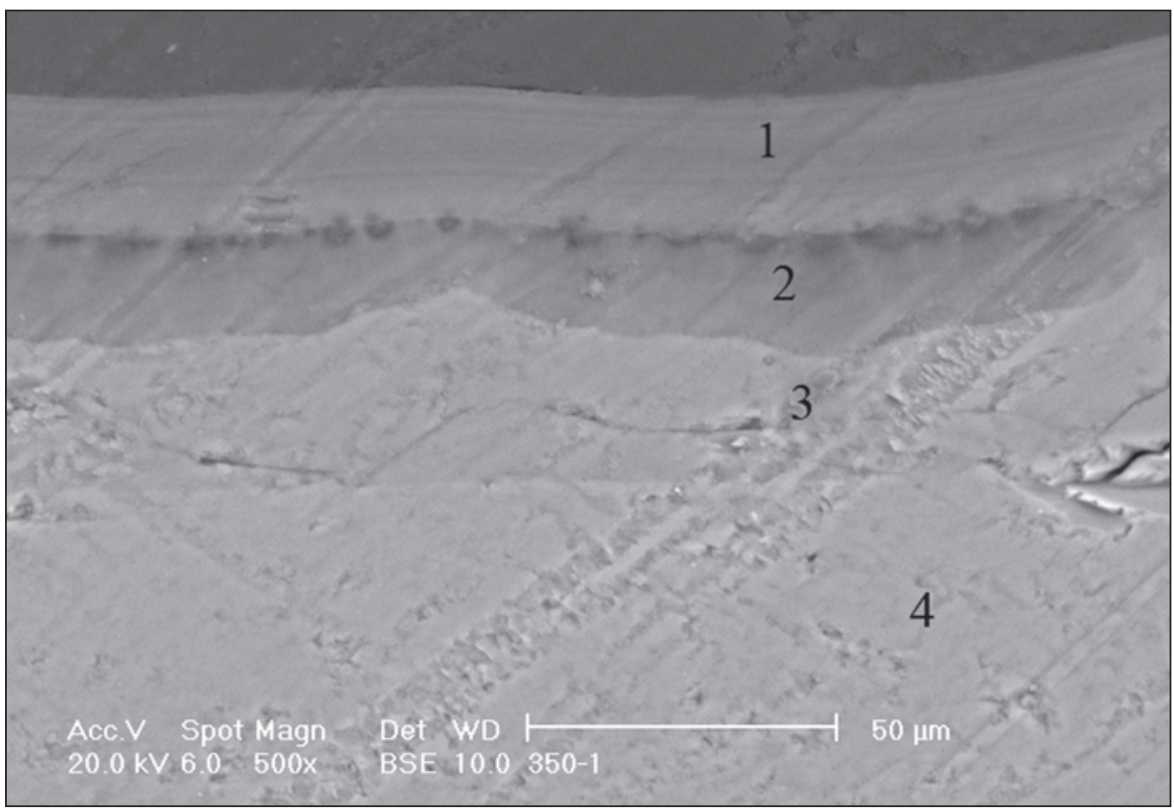

Figura 16: Fotomicrografía de SEM de electrones retrodispersados de una sección de la muestra de vidrio (SECYR350) de un pequeño cuenco de vidrio transparente. Se muestra las capas de corrosión $(1,2,3)$ y la matriz del vidrio (4). 


\section{RESUltadoS ANALÍTICOS Y DISCUSIÓN}

Las composiciones encontradas muestran que los fragmentos analizados poseen una composición típica romana de vidrios de silicato sódico-cálcicos y que no se usaron aditivos como colorantes, decolorantes u opacificantes, que hayan podido ser detectadas en nuestro estudio realizado con la técnica SEM-EDX.

En cuanto a los ingredientes utilizados para la fabricación de los vidrios, se aprecia que los valores de $\mathrm{K}_{2} \mathrm{O}$ y $\mathrm{MgO}$ son, en todos los casos presentados, inferiores a $1.5 \%$, con lo cual se deduce que los vidrios fueron fabricados con natrón como agente fundente.

Por otra parte, la presencia de los elementos $\mathrm{Fe}$, Ti y Al en el vidrio está relacionada con la utilización de arena como materia prima de partida, ya que este ingrediente contiene impurezas de minerales como la ilmenita $\left(\mathrm{FeTiO}_{3}\right)$ o feldespatos (Goffer, 2007: 111-134).

Finalmente, se sabe que la cal se incorporaba en el vidrio como impureza de la arena (por la presencia de fragmentos de conchas) o por la adición de conchas de mar o piedra caliza. No obstante, el alto contenido de $\mathrm{MgO}$ sugiere la utilización de dolomita (carbonato doble de calcio y magnesio, $\mathrm{CaMg}(\mathrm{CO} 3) 2$ ) como materia prima o impureza de la arena.

Una forma más documentada para descartar la utilización de conchas de mar, sería la determinación de $\mathrm{Sr}$, ya que las cochas incorporan fácilmente este elemento del agua de mar, sin embargo, dadas las condiciones del equipo SEM-EDX utilizado, no es posible su detección.

Con respecto a la coloración verde de los fragmentos SECYR338, SECYR340, SECYR343, SECYR344, SECYR346 y SECYR349, de acuerdo a los valores obtenidos para el $\mathrm{Fe}_{2} \mathrm{O}_{3}$, la coloración debe proceder de las impurezas de hierro presentes en la arena, y no del añadido de este mineral a la pasta base.

Aunque los fragmentos de la época bajoimperial SECYR335 y SECYR345 son incoloros, de acuerdo a los resultados analíticos no se observa la adición a la receta del vidrio de algún decolorante como trióxido de antimonio $\left(\mathrm{Sb}_{2} \mathrm{O}_{5}\right)$ o dióxido de manganeso $\left(\mathrm{MnO}_{2}\right)$, en cantidades significativas para ser detectadas con esta técnica.
Por otro lado, en la tabla de la figura 15 se observa la disminución en la cantidad de sodio en las capas superficiales con respecto a la matriz del vidrio. Dicho hecho confirma la pérdida de sodio en la superficie del material.

\section{CONCLUSIONES}

Una vez más, se pone de manifiesto la abundancia de vidrios que son recuperados en las excavaciones de la villa romana de El Saucedo. Tanto la cronología como el espectro formal registrado son muy amplios y variados. Como se ha apuntado en este estudio acotado en las campañas 2003 a 2006, no sólo son numerosas las piezas de la vajilla (cuencos, botellas, copas, ...), sino también elementos de adorno (cuentas de collar, pulseras, colgantes,...), además de los materiales constructivos para decoración en vidrio de diversos colores (vidrio de ventana, teselas vítreas, ...). A ellos habría que añadir algunos de restos de escorias del proceso productivo secundario. Quizás por ello, como una buena hipótesis de trabajo, pueda pensarse en la presencia de una officinae vitreorum, ya sea como taller permanente o, con más lógica, un taller temporal asentado en esta villa en determinado período del año, con capacidad productiva suficiente para abastecer a este establecimiento rural $\mathrm{y}$ a otros del entorno.

En razón de esta abundancia de restos de vidrios, que se puede apuntar, como algo bastante excepcional, en este yacimiento de El Saucedo de cronología tan dilatada es posible contar con suficientes muestras para desarrollar un amplio estudio analítico, del que este trabajo es un primer paso. A partir del estudio realizado sobre los vidrios con la técnica SEM-EDX se pudo determinar que los vidrios analizados de El Saucedo pertenecen al grupo de los sódico-cálcicos, patrón común en los vidrios romanos. Por medio de su composición química se estableció que fueron fabricados con natrón como agente fundente, arena como vitrificante y probablemente dolomita como agente estabilizante. Para un análisis más profundo, se requiere la complementación de los resultados presentados aquí con otras técnicas de análisis con mejores límites de detección y que permita la detección de elementos químicos de gran importancia tecnológica, como por ejemplo el estroncio. 


\section{BIBLIOGRAFÍA.}

ADRIAENS, A. (2005): "Non-destructive analysis and testing of museum objects: An overview of 5 years of research", SpectrochimicaActa Part B $60,1503-1516$.

ALONSO CEREZO, E. (2010): El vidrio romano en los Museos de Madrid. Tesis Doctoral. Universidad Complutense, Madrid.

BARRIO MARTÍN, J. (2002) “Aspectos de la investigación analítica sobre el deterioro y criterios de intervención en los vidrios romanos de la Villa de El Saucedo (Talavera la Nueva, Toledo)", Actas I Congreso del GEIIC(Grupo Español del International Institute for Conservation of Historic and Artistic Works), Valencia, Noviembre de 2002, 343-349.

BELTRÁN LLORIS, A. (2007) "Sustancias de procedencia arqueológica: eslabones recuperados para la investigación en arqueología", Caesaraugusta, 78, 769-780.

BENITEZ DE LUGO, L. y ÁLVAREZ GARCÍA, A. (2002) "Mentesa Oretana 2001-2002. Excavaciones arqueológicas en la $\mathrm{C} / \mathrm{Ciudad}$ Mentesa, 14 y 22; El callejón del aire, $\mathrm{n}^{\circ} 7$ (Villanueva de la Fuente, Ciudad Real)", en Investigaciones arqueológicas en Castilla-La Mancha (1996-2002), Consejería de Cultura, Toledo.

CABELLO BRIONES, A. (2008): Moneda e historia en tierras de Talavera de la Reina. Los hallazgos monetarios del yacimiento de El Saucedo (Talavera la Nueva, Toledo).

CALDERA DE CASTRO, Mª P. (1988) "Vidrios del museo arqueológico provincial de Cáceres", Anas, I, pp. 174-186.

CARMONA, N. ET ALII (2007): “Análisis de vidrios romanos del yacimiento de la Dehesa de La Oliva (Patones, Madrid)"; VII Congreso Ibérico de Arqueometría. Cerámica y vidrio, 319-328.

CISNEROS CUNCHILLOS, M. et al. (2004) "Estudio comparativo sobre aspectos cromáticos y decorativos del vidrio mosaico romano y marmora (s. I d.C.)", Jornadas sobre el vidrio en la España romana, Fundación Centro Nacional del Vidrio, $34-46$.

CORTÉS PIZANO, F. (2001) "Breve historia de las aplicaciones del vidrio plano en la construcción”, Revista del vidrio plano, 64, pp. 10-19.
FALOMIR VENTURA, C. (2005) "Vidrio romano: El solar de la plaza de la Morería de Sagunto", Rev. ARSE, 39, 125-144.

FREESTONE, I.C. (2005):"The Provenance of Ancient Glass through Compositional Analysis". Materials Research Society Symposium Proceedings 852, 1-14

FUENTES DOMÍNGUEZ, A. (1990) "Los vidrios de las necrópolis de la meseta. Ensayo preliminar de clasificación”, CUPAUAM, 17, pp. 169-202.

FUENTES DOMÍNGUEZ, A, (2001) "El vidrio y su uso en la arquitectura", Vidrio romano en España. La revolución del vidrio soplado, 137-145, Cuenca.

FUENTES DOMÍNGUEZ, A, (2001) "El vidrio. ¿Primer material reciclado de la historia”, Vidrio romano en España. La revolución del vidrio soplado, 147-149, Cuenca.

FUENTES DOMÍNGUEZ, A. (2007): "Vidrio de la Antigüedad tardía (ss.V-X). Cuestiones de fabricación y comercialización. Problemas de identificación" Vidrio islámico en Al-Andalus. 13-36. Madrid.

GERMÁN RODRÍGUEZ, F. y ALONSO CEREZO, E. (2005): "Lucernas. Antigüedades romanas, 2. Vidrios, Antigüedades romanas, 3." Catálogo del Gabinete de Antigüedades, Madrid.

GONZALEZ TASCÓN, I. (2002)“La ingeniería civil romana", Artifex. Ingenieria romana en España, 33-176, Madrid.

GOFFER, Z. (2007): Archaeological Chemistry, Edt. John Wiley \& Sons, 111-134, Nueva York

GUTIÉRREZ NEIRA, C. (2009) Aplicación de técnicas analíticas con haces de iones en la caracterización de materiales de interés arqueológico y artístico, 127-152. Tesis Doctoral. Universidad Autónoma de Madrid.

MADARIAGA GARCÍA, B. (2004) "Vidrio romano en los castros de occidente de Asturias", Jornadas sobre el vidrio en la España romana, Fundación Centro Nacional del Vidrio, 213-223,

MÄDER, M. et al. (1998): "Non-destructive evaluation of glass corrosion states", Nuclear Instruments and Methods in Physics Research B 136-138, 863-868. 
PALOP FERNÁNDEZ, L. (2007): Vidrios romanos en el Museo Cerralbo, Madrid.

PÉREZ ARANTEGUI, ET AL. (1996): “Analysis of the Products contained in two Roman glass ungüentaria from the Colony of Celsa (Spain)", Journal of Archeological Science, 23, 649-655.

ORTIZ PALOMAR, E. (2001) "Definición tecnológica y fabricación del vidrio antiguo", Vidrio romano en España. La revolución del vidrio soplado, pp. 8-61, Cuenca.

ORTIZ PALOMAR, E. (2001) "Vidrio antiguo y funcionalidad"”, Vidrio romano en España. La revolución del vidrio soplado, pp. 63-107, Cuenca.
ORTIZ PALOMAR, E. Y PAZ PERALTA, J.A. (1997) "El vidrio en los baños romanos", Termalismo Antiguo, 437-451, Madrid.

ROLDÁN ,L. ET ALII (2003): Carteia II. SIDI, http://www.uam.es/investigacion/servicios/sidi/es pecifica/barrido.html [Consulta 22/07/11]

SCHREINER, M. (2004): "Corrosion of historic glass and enamels", Janssens K, Van Grieken R (eds), Non Destructive Microanalysis of Cultural Heritage Materials, Comprehensive Analytical Chemistry XLII, Elsevier, 716,. Amsterdam. 
